\title{
Retrospective Audit of Medication Order Turnaround Time after Implementation of Standardized Definitions
}

\author{
Heather Naylor, Donna M M Woloschuk, Patrick Fitch, and Sarah Miller
}

\begin{abstract}
Background: Standardizing the interpretation of "stat", "emergent", "urgent", and "now" medication orders can improve patient safety. However, the effect of implementing standardized definitions on the turnaround time for medication orders in hospital pharmacy dispensaries has not been studied.
\end{abstract}

Objectives: To examine the effects of using formal definitions for "stat", "emergent", "urgent", and "now" on turnaround time for medication orders within a pharmacy dispensary.

Methods: Definitions for "stat", "emergent", "urgent", and "now" orders, as well as for "turnaround time", were developed from the formal literature and the grey literature. The definitions were implemented by educating all pharmacy staff. Retrospective audits of turnaround time were conducted at baseline (for all orders over a 1-month period) and after implementation of the definitions (for a total of 28 days over a 3-month period). Health records and medication orders were used to calculate time from prescribing to administration (total turnaround time) and time from prescribing to departure from the dispensary (dispensary turnaround time). Differences between total and dispensary turnaround times were compared with nonparametric statistics.

Results: During the baseline audit period, 84 (1.1\%) of 7787 orders were identified as "stat", "emergent", "urgent", or "now". After implementation of the formal definitions, $142(2.6 \%)$ of 5365 orders were identified by one of these terms. The percentage of orders meeting the target dispensary turnaround time of less than $15 \mathrm{~min}$ was at least $90 \%$ both at baseline $(76 / 84[90 \%])$ and after implementation $(129 / 142$ [91\%]) $(p=0.80)$. Median dispensary turnaround time for stat and emergent medication orders combined (10 versus $9 \mathrm{~min}, p=0.27$ ) and for urgent and now medication orders combined (10 versus $12 \mathrm{~min}, p=0.09$ ) did not change after implementation of formal definitions. Similarly, median total turnaround time did not change for stat and emergent medication orders combined ( 30 versus $45 \mathrm{~min}, p=0.32$ ), but it increased for urgent and now orders combined ( 35 versus $45 \mathrm{~min}, p=0.041$ ).

Conclusions: Implementing standardized definitions for "stat", "emergent", "urgent", and "now" had no significant effect on dispensary turnaround time. However, the majority of orders with these designations met the expected target for dispensary turnaround time. Further interventions aimed at other health care professionals may be needed to reduce total turnaround time. This research supports the concept of interdisciplinary interventions for reducing total turnaround time.

Key words: turnaround time, medication, stat, urgent

\section{RÉSUMÉ}

Contexte : La standardisation de l'interprétation des termes "stat", " emergent ", " urgent " et " now " pour qualifier le degré d'urgence des ordonnances de médicaments peut améliorer la sécurité des patients. Cependant, l'effet de la mise en place de définitions standardisées sur le délai d'exécution des ordonnances de médicaments dans les pharmacies d'hôpitaux n'a pas été étudié.

Objectifs : Analyser les effets de l'utilisation de définitions standardisées des termes "stat ", " emergent ", "urgent » et " now » sur le délai d'exécution des ordonnances de médicaments au sein d'un service de pharmacie d'hôpital.

Méthodes : Une définition des termes "stat ", " emergent ", " urgent " et " now " utilisés sur les ordonnances, de même que de "délai d'exécution " a été établie à partir de la documentation officielle ainsi que de la documentation parallèle. La définition de ces termes a été mise en œuvre au moyen d'une formation de tout le personnel de la pharmacie. Des vérifications rétrospectives des délais d'exécution ont été menées avant (pour toutes les ordonnances sur une période d'un mois) et après la mise en œuvre des définitions (pour un total de 28 jours sur une période de trois mois). Les dossiers médicaux et les ordonnances de médicaments ont été utilisés pour calculer le temps écoulé entre la rédaction de l'ordonnance jusqu'à l'administration du médicament (délai total d'exécution) et le temps écoulé entre la rédaction de l'ordonnance et le moment où le médicament quitte la pharmacie de l'hôpital (délai d'exécution par la pharmacie de l'hôpital). Les différences entre le délai total d'exécution et le délai d'exécution par la pharmacie de l'hôpital ont été comparées au moyen de statistiques non paramétriques.

Résultats : Durant la période initiale de vérification, 84 (1,1\%) des 7787 ordonnances ont été qualifiées de "stat", " emergent ", "urgent " ou " now ". Après la mise en œuvre des définitions standardisées, 142 (2,6\%) des 5365 ordonnances ont satisfait la définition d'un de ces termes. Le pourcentage d'ordonnances exécutées par la pharmacie de l'hôpital dans le délai prévu de moins de 15 minutes était d'au moins $90 \%$ pour les vérifications avant (76/84 ou $90 \%)$ et après la mise en œuvre des définitions standardisées $(129 / 142$ ou $91 \%)(p=0,80)$. Le délai médian d'exécution par la pharmacie de l'hôpital des ordonnances "stat » et "emergent " combinées (10 contre $9 \min , p=0,27)$ et des ordonnances "urgent " et " now " combinées (10 contre $12 \mathrm{~min}, p=0,09)$ n'a pas changé après la mise en œuvre des définitions standardisées. De même, le délai d'exécution total médian n'a pas changé pour les ordonnances "stat " et "emergent " combinées ( 30 contre $45 \mathrm{~min}, p=0,32$ ), mais a augmenté pour les ordonnances « urgent» et «now» combinées (35 contre $45 \mathrm{~min}, p=0,041$ ). 
Conclusions : La mise en ouvre de définitions standardisées pour les ordonnances "stat ", " emergent ", « urgent " et " now » n'a pas eu d'influence considérable sur le délai d'exécution par la pharmacie de l'hôpital. En revanche, la majorité des ordonnances ainsi désignées ont été exécutées par la pharmacie de l'hôpital dans le délai prévu. D'autres interventions ciblant d'autres professionnels de la santé pourraient être nécessaires pour réduire le délai total d'exécution. Cette recherche confirme le concept d'interventions interdisciplinaires pour réduire le délai total d'exécution.

Mots clés : délai d'exécution, médicaments, stat, urgent

[Traduction par l'éditeur]

\section{INTRODUCTION}

$\mathrm{I}^{\mathrm{n}}$ nterpretation of orders designated "stat", "emergent", "urgent", and "now" determines the timelines within which a medication is made available and ultimately administered to the patient. The definitions of these terms also guide the organization of workflow for each health care professional involved in the medication-use cycle. The need for predefined operational definitions for "stat", "emergent", "urgent", and "now" is well described in the literature. ${ }^{1,2}$ The Canadian Council on Health Services Accreditation (now Accreditation Canada) stated in its 2008 Managing Medications accreditation standards that the pharmacy must "address definitions of and dispensing times for emergency, urgent, and routine medications" for the purposes of improving patients' access to care. ${ }^{3}$ Although many organizations have established target dispensing or medication administration turnaround time frames for the terms "stat", "emergent", "urgent", and "now", singling out specific medications such as antibiotics that should be handled as stat, emergent, urgent, or now often remains at the discretion of the person writing or interpreting the medication order.

The Institute for Safe Medicine Practices ${ }^{4}$ has identified standardizing the interpretation of these 4 terms as a specific avenue for improving patient safety practices. This organization recommends that turnaround times for medication orders, defined as an interval representing the period required for a medication order to be processed, be consistent with established targets for emergent, urgent, and routine medications. Although the effect of various interventions on turnaround time has been evaluated by other researchers, ${ }^{5-11}$ the effect of implementing standardized definitions for "stat", "emergent", "urgent", and "now" and of establishing standardized order-processing practices within hospital pharmacy dispensaries has not yet been studied.

The absence of standardized definitions for orders that are needed quickly can lead to inconsistency in patients' access to care, as measured by turnaround time for medication orders. The literature indicates that patient outcomes are improved by reducing medication turnaround time. For example, timely administration of first-dose antibiotics in the emergency department decreased patients' length of stay in hospital. ${ }^{12}$ It was therefore hypothesized that creating a more clearly defined process for medication-order processing by standardizing definitions of "stat", "emergent", "urgent", and "now" within hospital pharmacies would help to enhance patient safety, as measured by more timely access to care. It was anticipated that standard definitions would also provide targets for turnaround time for orders in each category and facilitate measuring whether standard definitions improved patients' timely access to medication therapy. The purpose of this audit was to determine whether implementation of formal definitions for "stat", "emergent", "urgent", and "now" orders affected turnaround time for medications within a hospital pharmacy dispensary.

\section{METHODS}

This study was conducted at a 231-bed community hospital in Winnipeg, Manitoba, which provides care to acutely ill medical-surgical, mental health, and family medicine patients. Formal definitions for "stat", "emergent", "urgent", and "now" orders and for turnaround times were developed from both the formal (i.e., published) and grey literature and feedback from pharmacy personnel at a facility not involved in the audit (Appendix 1). A retrospective audit of turnaround times for medication orders meeting the definitions of "stat", "emergent", "urgent", and "now" was then conducted. The audit was based on all prescriptions received in the pharmacy dispensary during normal operational hours (0700-2100) for patients admitted to hospital on days selected for auditing. According to standard pharmacy workflow, orders received in the pharmacy dispensary arrived on the regular fax machine or a fax machine reserved for stat orders. Inclusion criteria for arrival on the stat fax included order being designated as "stat" or "now" by the prescriber or order being triaged as "urgent" by the nursing staff or a ward clerk. At the time of the audit, formal definitions for "stat", "emergent", "urgent", and "now" 
orders were not available to hospital personnel other than pharmacy staff. All orders received in the pharmacy dispensary were triaged and entered by a pharmacist. Orders for non-wardstock medications were filled by a pharmacy technician and checked by a pharmacist before being sent to the ward on a scheduled medication delivery. Pharmacy staff members' usual practice of time-stamping medication orders after final check by a pharmacist was maintained throughout the audit period. However, staff members were asked to modify usual dispensary practices by documenting the time of receipt of each medication order and the time of delivery using an electronic time stamp.

The audit was carried out in 2 stages: baseline and post-intervention. The baseline audit covered all prescriptions for patients admitted to hospital that were received during normal pharmacy hours during the month of May 2009. During this baseline period, pharmacy personnel were not informed about the pharmacy definitions for "stat", "emergent", "urgent", and "now" or the medication orders that were being selected for audit. Between the baseline and postintervention periods, all pharmacy personnel participated in a mandatory in-service about implementation of standardized definitions for handling stat/emergent and urgent/now medication orders. The post-intervention audit was based on all prescriptions for patients admitted to hospital that were received during normal pharmacy hours on 28 randomly selected days between August 17 and October 9, 2009. As before, pharmacy personnel were not informed about the specific dates on which medication orders would be selected for audit. During both the baseline and post-intervention periods, usual dispensary work practices were maintained, with the exception of a supervisor drawing the attention of all personnel to the need for consistent documentation of order receipt, final check, and delivery time and date stamps. Selection bias and confounding were minimized by collecting data for $100 \%$ of prescriptions on prespecified days, in addition to not directly informing pharmacy personnel which prescriptions were being selected for audit.

Audit data were collected from copies of medication orders stored within the hospital pharmacy department. Medication orders were excluded from audit if one or more of the following exclusion criteria were met: order did not meet the definition for "stat", "emergent", "urgent", or "now"; order was illegible; or order documentation was insufficient to calculate dispensary and total turnaround times (e.g., time that order was received in pharmacy was not documented with time and date stamps). All orders meeting inclusion criteria (and not excluded by exclusion criteria) were reviewed to obtain pertinent data, as listed in Appendix 2. Patient health records associated with medication orders that met the inclusion criteria were reviewed to ascertain the time of medication administration, as document- ed in the medication administration record, to allow calculation of total turnaround time.

\section{Primary and Secondary Outcomes}

The primary outcome was an evaluation of differences in median dispensary turnaround time for stat/emergent and urgent/now orders before and after implementation of the standardized definitions. The secondary outcome was determination of differences in median total turnaround time for stat/emergent and urgent/now orders before and after implementation of the standardized definitions.

\section{Sample Size}

A pilot audit of stat, emergent, urgent, and now orders was conducted over a 30-day period during March 2009 to estimate sample size for this study. Using data from the pilot audit, it was estimated that a sample size of 300 orders per study period would have $80 \%$ power to detect a $30 \%$ improvement in turnaround time ( $\alpha=0.05$, one-sided).

\section{Data Analysis}

Stat/emergent and urgent/now orders with sufficient data to calculate dispensary and total turnaround times were included in the analysis. The data were collated into a database created in Microsoft Excel. The proportion of stat, emergent, urgent, and now orders meeting the target dispensary turnaround time of $15 \mathrm{~min}$ or less was calculated, along with the median dispensary and total turnaround times for stat, emergent, urgent, and now orders included in the baseline and postintervention audit periods. Differences in dispensary and total turnaround times were compared with Mann-Whitney tests for nonparametric data.

A post hoc subgroup analysis was performed after completion of data analysis per protocol to gather further insight into the primary results. Differences in median dispensary and total turnaround times by medication category (e.g., antimicrobials, antithrombotics, vasopressors) were compared with MannWhitney tests.

The study protocol was approved by the University of Manitoba Bannatyne Campus Research Ethics Board. No patients were approached for the purposes of obtaining data related to this audit.

\section{RESULTS}

\section{Prevalence of Orders Meeting the Standardized Definitions}

A total of 7787 prescriptions were included in the baseline audit and 5365 prescriptions in the post-intervention audit (Table 1). Overall, 84 (1.1\%) of the medication orders audited 


\section{Table 1. Characteristics of Prescriptions Included in Study of Medication Order} Turnaround Times

\begin{tabular}{|c|c|c|c|c|}
\hline \multirow[b]{2}{*}{ Characteristic } & \multicolumn{3}{|c|}{ Study Period; No. (\%) of Prescriptions* } & \multirow[b]{2}{*}{$p$ Value } \\
\hline & Baseline & Post-Inte & ervention & \\
\hline No. of prescriptions & 7787 & \multicolumn{2}{|c|}{5365} & \\
\hline Orders meeting SEUN* definitions & $84(1.1)$ & 142 & $(2.6)$ & $<0.001$ \\
\hline \multicolumn{5}{|l|}{ Method of arrival in pharmacy } \\
\hline Regular fax & $6 \quad(7)$ & 49 & (35) & $<0.001$ \\
\hline Stat fax & $78(93)$ & 93 & (65) & $<0.001$ \\
\hline Stat/emergent orders & $30(36)$ & 37 & (26) & 0.11 \\
\hline Stat & $26(87)$ & 28 & (76) & 0.26 \\
\hline Antithrombotics & $2 \quad(7)$ & 7 & (19) & 0.15 \\
\hline Other & $2(7)$ & 2 & (5) & 0.75 \\
\hline Urgent/now orders & $54(64)$ & 105 & (74) & 0.11 \\
\hline Now & 41 (76) & 73 & (70) & 0.42 \\
\hline First-dose antimicrobials & $5 \quad(9)$ & 27 & (26) & 0.025 \\
\hline Other & $8(15)$ & 5 & (5) & 0.031 \\
\hline
\end{tabular}

SEUN = stat, emergent, urgent, now.

* Percentages within each subgroup are calculated on the basis of number of prescriptions in the subgroup (not total number of prescriptions).

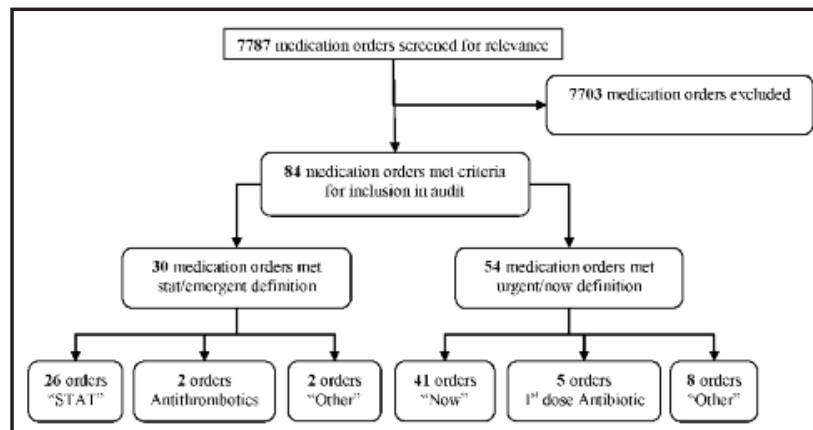

Figure 1. Flow chart of medication order audit before implementation of standardized definitions of "stat", "emergent", "urgent" and "now" (baseline).

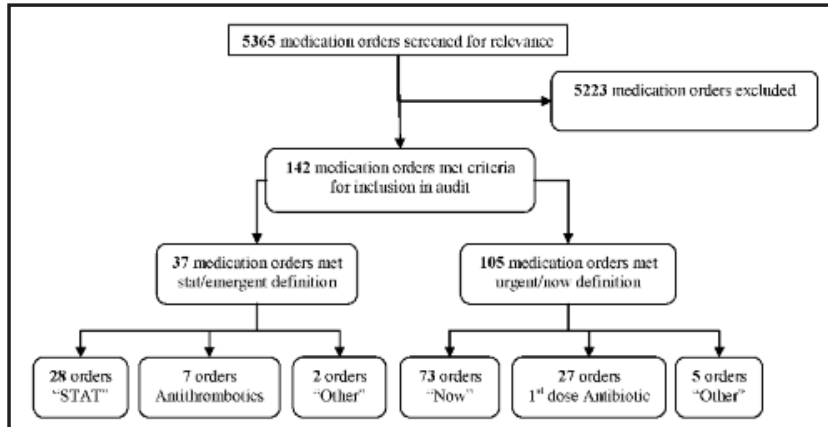

Figure 2. Flow chart of medication order audit after implementation of standardized definitions of "stat", "emergent", "urgent" and "now".

in the baseline period (Figure 1) and $142(2.6 \%)$ of those audited in the post-intervention period (Figure 2) were designated "stat", "emergent", "urgent", or "now".
Less than $1 \%$ of excluded baseline orders $(50 / 7703)$ and $1.6 \%$ of excluded post-intervention orders (85/5223) were exempted from data analysis because of insufficient documentation to calculate dispensary or total turnaround time, even though they met the criteria for a stat, emergent, urgent, or now order. Examples of incomplete documentation included absence of the time the medication order was written by the prescriber or absence of an administration time documented in the medication administration record.

\section{Dispensary and Total Turnaround Times}

The primary outcome measure in this study was median dispensary turnaround time for stat/emergent and urgent/now orders. Median dispensary turnaround time did not change after implementation of standardized definitions for either "stat"/“emergent" medications (10 versus $9 \mathrm{~min}, p=0.27$ ) or "urgent"/"now" medications (10 versus 12 minutes, $p=0.09$ ) (Figure 3, Table 2). Notably, although the target dispensary turnaround time for urgent/now orders was $60 \mathrm{~min}$ or less, the majority of all orders (stat/emergent and urgent/now) achieved a dispensary turnaround time of $15 \mathrm{~min}$ or less at baseline (76/84 or $90 \%)$ and after implementation (129/142 or $91 \%)$ $(p=0.80)$.

The secondary outcome measure in this study was median total turnaround time for stat/emergent and urgent/now orders. The median total turnaround time for stat/emergent medication orders did not change after implementation of the standardized definitions (30 versus $45 \mathrm{~min}, p=0.32$ ). However, median total turnaround time for urgent/now medication orders increased after implementation of the standardized definitions (35 versus $45 \mathrm{~min}, p=0.041$ ). 


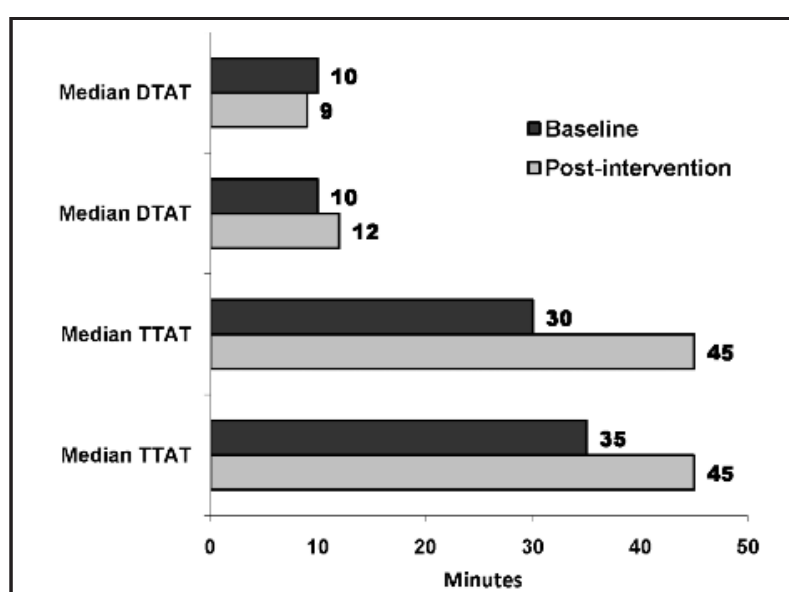

Figure 3. Dispensary turnaround time (DTAT) and total turnaround time (TTAT) before and after implementation of formal definitions of "stat", "emergent", "urgent" and "now".

\section{Subgroup Analysis}

The small sample size of most medication categories prevented subgroup analyses except for antimicrobial medications, for which there were 9 orders in the baseline audit period and 41 in the post-intervention period (Table 3). Median dispensary turnaround time for antimicrobial orders did not change with implementation of standardized definitions (10 versus $16 \mathrm{~min}, p=0.14$ ). However, median total turnaround time increased for orders for this group of medications ( 35 versus $115 \mathrm{~min}, p=0.027$ ) after implementation of the formal definitions.

The effect of formal definitions for "stat", "emergent", "urgent", and "now" on median dispensary and total turnaround times for all medications other than antimicrobials was also measured. For these medications, median dispensary turnaround time did not change with implementation of the standardized definitions: 9 versus $8 \min (p=0.29)$ for stat/ emergent medication orders and 11 versus $10 \min (p=0.32)$ for urgent/now medication orders. In addition, there was no change in median total turnaround time for stat/emergent orders (30 versus $30 \mathrm{~min}, p=0.53$ ) or urgent/now orders (36 versus $40 \mathrm{~min}, p=0.08$ ) with exclusion of antimicrobial orders.

\section{DISCUSSION}

In this audit of turnaround times for medication orders, there was no significant decrease in total or dispensary turnaround time with implementation of standard definitions for "stat", "emergent", "urgent", and "now". However, the majority of stat and emergent orders combined and of urgent and now orders combined met the target dispensary turnaround time for stat/emergent orders (15 min or less). An unanticipated finding of the study was the statistically significant increase in total turnaround time for urgent/now orders after implementation of the standardized definitions.

These results suggest that implementation of formal definitions for "stat", "emergent", "urgent", and "now" orders within a hospital pharmacy dispensary was ineffective in improving medication turnaround time. However, because of the small sample size, a type II error is a possibility. Sample-size calculations estimated that 300 orders per study period would have $80 \%$ power to detect a $30 \%$ improvement in turnaround time. As such, both the baseline and post-intervention audit periods were underpowered to detect a statistically significant improvement in turnaround time, given that there were only 84 orders designated stat, emergent, urgent, or now in the baseline period and 142 such orders in the post-intervention period.

An unanticipated finding of this study was the statistically significant increase in total turnaround time for urgent/now orders. On the basis of these results, we speculate that the null hypothesis is true, i.e., that implementation of standard definitions for "stat", "emergent", "urgent", and "now" orders increased medication turnaround time. However, the pharmacy was the only department in the study hospital made aware of the standardized definitions, and dispensary turnaround time

Table 2. Turnaround Times for Medication Orders

\begin{tabular}{|c|c|c|c|}
\hline Characteristic & Baseline & Post-Intervention & $p$ Value \\
\hline Stat/emergent orders & $n=30$ & $n=37$ & \\
\hline Median dispensary turnaround time (min) & 10 & 9 & 0.27 \\
\hline $\begin{array}{l}\text { No. (\%) with dispensary turnaround } \\
\text { time }<15 \mathrm{~min}\end{array}$ & $28(90)$ & $35(95)$ & 0.43 \\
\hline Median total turnaround time (min) & 30 & 45 & 0.32 \\
\hline Urgent/now orders & $n=54$ & $n=105$ & \\
\hline Median dispensary turnaround time (min) & 10 & 12 & 0.09 \\
\hline $\begin{array}{l}\text { No. (\%) with dispensary turnaround } \\
\text { time }<15 \mathrm{~min}\end{array}$ & $48(89)$ & $94(89)$ & 0.10 \\
\hline $\begin{array}{l}\text { No. (\%) with dispensary turnaround } \\
\text { time }<60 \text { min }\end{array}$ & $41(94)$ & $101(96)$ & 0.57 \\
\hline Median total turnaround time (min) & 35 & 45 & 0.041 \\
\hline
\end{tabular}


Table 3. Subgroup Analysis of Antibiotic Medication Orders

\begin{tabular}{lccc} 
Characteristic & Baseline & Post-Intervention & $\boldsymbol{p}$ Value \\
\hline No. of orders & 9 & 41 & \\
\hline Method of arrival in pharmacy & $2(22)$ & $22(54)$ & 0.08 \\
$\quad$ Regular fax & $7(78)$ & $19(46)$ & 0.08 \\
$\quad$ Stat fax & $2(22)$ & $7(17)$ & 0.72 \\
Orders meeting SEUN* definition & $2(22)$ & $8(20)$ & 0.89 \\
Stat & $5(56)$ & $26(63)$ & 0.70 \\
Now & 10 & 16 & 0.14 \\
First-dose parenteral antibiotic & 35 & 115 & 0.027 \\
\hline Median dispensary turnaround time (min) & & &
\end{tabular}

SEUN = stat, emergent, urgent, now.

did not increase from baseline following education of pharmacy staff about the definitions. Given that education about the standardized definitions of "stat", "emergent", "urgent", and "now" was not provided to all health care professionals contributing to total turnaround times for medication orders, it is unlikely that implementation of these definitions was responsible for the increase in total turnaround time. Instead, we hypothesize that a reduction in scheduled medication deliveries to patient wards in the post-intervention audit period, secondary to loss of volunteer services, may explain the increase in total turnaround time.

On the basis of these findings, we hypothesize that future interventions may need to be extended to other health care professionals in order to affect total turnaround time. In this study, pharmacy staff met expected targets for dispensary turnaround time for at least $90 \%$ of orders. However, there was no effect on total turnaround time with implementation of standard definitions for "stat", "emergent", "urgent", and "now" orders. As is evident from the results of the study, pharmacy controls the rate of departure of medications from the dispensary (i.e., dispensary turnaround time), but the rate of medication administration to the patient is beyond pharmacy's control. Extending education about standardized definitions for "stat", "emergent", "urgent", and "now" to other health care professionals involved in the medication administration process (e.g., nurses, physicians) with the goal of improving total turnaround time therefore warrants future study.

Providing education about turnaround times for medication orders to health care professionals has been shown to improve turnaround times and patient outcomes. The First Dose Antibiotic program was implemented in September 2007 at the Health Sciences Centre in Winnipeg. ${ }^{13}$ This program consisted of mandatory education sessions for all pharmacy staff about the importance of timely first doses of antibiotics. The average dispensary turnaround time from receipt of orders to exit of antibiotics from the pharmacy decreased from 80 to $34 \mathrm{~min}(p<0.001)$ and the number of days in hospital decreased from 4.8 to $2.8(p=0.01) \cdot{ }^{13}$ Application of these findings is limited, as the results pertain only to dispensary turnaround time. However, offering education sessions to other health care professionals about the importance of timely administration of stat, emergent, urgent, and now medications such as antibiotics may also aid in decreasing total turnaround time.

The strengths of the study reported here included minimization of selection bias by collecting data for $100 \%$ of prescriptions and use of standardized definitions for "stat", "emergent", "urgent", and "now" that were designed for simplicity. The limitations of this study were a below-expected sample size, due to missing data in the health records (observed power of 60\%), and limited generalizability to patients outside the acute care setting. The study was underpowered, and it is therefore possible that a statistically significant difference in dispensary turnaround time might have been found, had a greater number of medication orders been included in the audit.

Although the effects on turnaround time of implementing standardized definitions for "stat", "emergent", urgent", and "now" and for order-processing practices within hospital pharmacy dispensaries have not been previously evaluated, actual turnaround time for stat, emergent, urgent, and now medication orders in the current study were consistent with previously published turnaround time targets. Among US centres, medication turnaround time has been defined as $15 \mathrm{~min}$ for stat/emergent orders and $60 \mathrm{~min}$ for urgent/now orders. ${ }^{14-16}$ In the current study, a turnaround time of $15 \mathrm{~min}$ was achieved for at least $90 \%$ of orders for both dispensary and total turnaround times. Our standardized definitions of "stat", "emergent", "urgent", and "now" are thus in compliance with Accreditation Canada standards to "address definitions of and dispensing times for emergency, urgent, and routine medications."

\section{CONCLUSIONS}

Implementing standardized definitions for "stat", "emergent", "urgent", and "now" medication orders did not have a significant effect on dispensary turnaround time. However, the 
majority of orders designated with one of these terms met the expected target for dispensary turnaround time. This study demonstrates the necessity of interdisciplinary interventions for reducing total turnaround time.

\section{Note Added in Proof}

Subsequent to completion of this project, slightly modified definitions for "stat", "emergent", "urgent", and "now" orders were adopted by all pharmacies in the Winnipeg Regional Health Authority. In the revised definition, naloxone, Digibind (digoxin immune Fab), and flumazenil are treated as stat or emergent agents. In all other respects, the definitions remain unchanged.

\section{References}

1. Barker KN, Harris JA, Webster DB, Stringer JF, Pearson RE, Mikeal RL, et al. Consultant evaluation of a hospital medication system: synthesis of a new system. Am J Hosp Pharm 1984;41(10):2016-2021.

2. Maddock JR, Hanson LB. Application of quality improvement techniques to the reduction of turnaround time for "STAT" and "ASAP" orders. Hosp Pharm 1993;28(7):640-644.

3. Canadian Council on Health Services Accreditation. Managing medications standards. Ottawa (ON): Accreditation Canada; 2008.

4. Measuring up to medication safety. Horsham (PA): Institute for Safe Medication Practices; 2005 [cited 2009 Dec 10]. Available from: www.ismp.org/newsletters/acutecare/articles/20050310.asp

5. Weber RJ, Skledar SJ, Sirianni CR, Frank S, Yourich BY, Martinelli B. The impact of hospital pharmacist and technician teams on medication-process quality and nurse satisfaction. Hosp Pharm 2004;39(12):1169-1176.

6. Kilsdonk GF, Henke LW, Perley DL. Process improvements to decrease pharmacy turnaround time. Hosp Pharm 2001;36(7):750-752.

7. Reynolds DM, Johnson MH, Longe RL. Medication delivery time requirements in centralized and decentralized unit dose drug distribution systems. Am J Hosp Pharm 1978;35(8):941-943.

8. Hibbard FJ, Bosso JA, Sward LW, Baum S. Delivery time in a decentralized pharmacy system without satellites. Am J Hosp Pharm 1981;38(5): 690-692.

9. Huffman MD, Cummins JM. Providing 24-hour pharmaceutical services with mobile medication carts. Am J Hosp Pharm 1986;43(6):1504-1506.

10. Lomonte PJ, Besser RA, Thomas EC. Effect of decentralized computer order entry on medication turnaround time. Am J Hosp Pharm 1983; 40(6):979-981.
11. Thomas JA, Martin V, Frank S. Improving pharmacy supply-chain management in the operating room. Healthc Financ Manage 2000; 54(12):58-61.

12. Huang JQ, Hooper PM, Marrie TJ. Factors associated with length of stay in hospital for suspected community-acquired pneumonia. Can Respir J 2006;13(6):317-24.

13. Caligiuri C, Green M, Cecon J, Carroll L. Implementation of a first dose antibiotic pharmacy program to ensure timely delivery of antibiotics to patient care areas. Can J Hosp Pharm 2009;62(4):344.

14. Medical records content/documentation. Shreveport (LA): Louisiana State University Health Sciences Center; 1994 [revised 2010 May; cited 2009 Dec 10]. Available from: www.sh.lsuhsc.edu/policies/ policy_manuals_via_ms_word/hospital_policy/h_6.5.0.pdf

15. Reilly R, Massoomi F, Danekas P. Medication order turnaround defined. Methodist Hosp Pharm Therapeut Update 2005;12:1.

16. Medication order turnaround time policy. Lexington (KY): University of Kentucky Hospital, Chandler Medical Centre, Department of Pharmacy; 1992 [updated 2009 June; cited 2009 Dec 10]. Available from: www.hosp.uky.edu/pharmacy/departpolicy/PH04-11.pdf

Heather Naylor, BScPharm, ACPR, is with the Winnipeg Regional Health Authority Pharmacy Program, Seven Oaks General Hospital Site, Winnipeg, Manitoba.

Donna M M Woloschuk, BSP, PharmD, MDE, FCSHP, is with the Winnipeg Regional Health Authority Pharmacy Program, Winnipeg, Manitoba.

Patrick Fitch, BSP, ACPR, is with the Winnipeg Regional Health Authority Pharmacy Program, Victoria General Hospital Site, Winnipeg, Manitoba.

Sarah Miller, BSP, ACPR, was, at the time this work was completed, with the Winnipeg Regional Health Authority Pharmacy Program, Grace Hospital Site, Winnipeg, Manitoba.

\section{Address correspondence to:}

Heather Naylor

WRHA Pharmacy Services

Seven Oaks General Hospital

2300 McPhillips Street

Winnipeg MB R2V $3 M 3$

e-mail: hnaylor@dal.ca

\section{Acknowledgement}

The contributions of Colette Raymond to this project are gratefully acknowledged. 


\section{Appendix 1. Definitions}

Term

Total turnaround time

Dispensary turnaround time

Wardstock medication

Medication order triage

\section{Stat/emergent order}

All orders meeting the above criteria

will have an expected pharmacy

turnaround time of 15 minutes

\section{Definition}

Time it takes for a medication order to be processed, typically from the time an order is written or electronically prescribed until the drug is available to a practitioner for administration to a patient.

Time a medication order is received in the pharmacy to the time the medication leaves the dispensary.

Medication made available in a controlled storage location in a patient care area that can be given to a patient with a valid medication order in advance of the medication order being reviewed by a pharmacist.

The process of prioritizing medication orders for computerized order entry into a pharmacy information system, preparation of the product for dispensing, and delivery to the point of care according to a perceived level of urgency within the pharmacy department

Any order for a non-wardstock medication which meets at least one of the following criteria:

- written as "Stat" or "Emergency"

- vasopressors (i.e., dopamine, dobutamine, vasopressin)

- thrombolytics or antithrombotics not for prophylactic use

- nitroglycerin sublingual (tabs, spray) ordered $\times 1$ dose

- epinephrine ordered $\times 1$ dose

Urgent/now (UN) order All orders meeting the above criteria will have an expected pharmacy turnaround time of 1 hour.
Any order for a non-wardstock medication which meets at least one of the following criteria:

- written as "Now", "ASAP" or "Urgent"

- first-dose parenteral antibiotics

- first-dose narcotics

- electrolyte solutions

- antidotes ordered $\times 1$ dose (i.e., vitamin K, naloxone, activated charcoal,

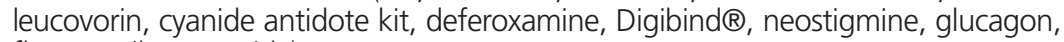
flumazenil, octreotide)

- loading dose of any drug

\section{Appendix 2. Data obtained from medication orders}

- Patient health record number

- Criteria, per the "stat", "emergent", "urgent", and "now" definitions, for including the medication order in the audit

- Medication order as written

- Method of arrival of medication order in the pharmacy (regular fax machine vs. fax machine reserved for "stat" medication orders)

- Notes documented by pharmacy personnel on the medication order

- Time the order was written by a prescriber

- Time the order was received in the pharmacy

- Time the product was checked by a pharmacist

- Time the patient care unit was notified that the order was ready for pick-up

- Time the product left the pharmacy 